\title{
COGNIÇÃO EMPREENDEDORA: ELEMENTOS COGNITIVOS QUE INFLUENCIAM A EXPLORAÇÃO DE OPORTUNIDADES
}

\author{
iD Gustavo Behling ${ }^{1}$ (iD Fernando César Lenzi ${ }^{2}$ \\ ${ }^{1}$ Universidade do Vale do Itajaí - UNIVALI, Itajaí, SC, Brasil.behling@univali.br \\ ${ }^{2}$ Universidade do Vale do Itajaí - UNIVALI, Itajaí, SC, Brasil.lenzi@ univali.br
}

\section{Resumo}

Objetivo do estudo: Apresentar uma abrangente revisão de literatura sobre os elementos cognitivos que influenciam os modelos mentais de empreendedores na exploração de oportunidades.

Metodologia/abordagem: Os procedimentos metodológicos empregados nesta pesquisa bibliográfica foram divididos em: 1 . Formulação da questão de pesquisa, 2. Localização dos estudos, 3. Seleção e avaliação dos estudos, 4. Análises e síntese e 5. Relato dos resultados. A busca dos estudos resultou em 87 artigos identificados. $\mathrm{Na}$ etapa de seleção e avaliação, 36 artigos foram excluídos devido à falta de aderência à temática pretendida. Com 51 artigos selecionados, foi realizada uma leitura criteriosa dos documentos. Por fim, os autores realizaram a revisão e análise apresentada nos resultados.

Originalidade/Relevância: Há uma carência de estudos sobre como variações em elementos cognitivos moldam as percepções dos empresários sobre oportunidades empreendedoras. O estudo evidencia a diversidade de oportunidades de pesquisa em cognição empreendedora, contribuindo para o campo de estudos.

Principais resultados: $\mathrm{O}$ artigo apresenta dez características cognitivas de empreendedores que suportam seus modelos mentais e influenciam o processo de exploração de oportunidades. A partir das análises destas características, são sugeridas oito proposições teóricas a serem testadas empiricamente que podem gerar um melhor entendimento sobre os modelos mentais de empreendedores.

Contribuições teóricas/metodológicas: A revisão de literatura apresentada, e em maior grau as proposições levantadas a partir desta, revela uma série de lacunas de pesquisa e pontos que carecem de aprofundamento em estudos empíricos para desenvolver um melhor entendimento sobre como características cognitivas interferem na identificação e exploração de novos de negócios.

Palavras-chave: Oportunidades empreendedoras. Cognição Empreendedora. Modelos mentais.

\section{ENTREPRENEURIAL COGNITION: COGNITIVE ELEMENTS} THAT INFLUENCE THE EXPLORATION OF OPPORTUNITIES

\section{Abstract}

Objective: To present a review of the literature on the cognitive elements that influence the mental models of entrepreneurs in the exploration of opportunities.

Methodology / approach: The methodological procedures used in this bibliographic research were divided into: 1. Formulation of research question, 2. Location of studies, 3. Selection and evaluation of studies, 4. Analysis and synthesis and, 5. Report of results. The search for the studies resulted in 87 identified articles. In the selection and evaluation stage, 36 articles were excluded due to the lack of adherence to the intended theme. With 51 articles selected, a careful reading of the documents was carried out. Finally, the authors achieved the review and analysis presented in the results.

Originality / Relevance: There is a lack of studies on how variations in cognitive elements shape the perceptions of entrepreneurs about opportunities. The study evidences the diversity of lacks in entrepreneurial cognition field of studies.
Main results: The paper presents ten cognitive characteristics of entrepreneurs who support their mental models and influence the process of exploring opportunities. From the analyzes of these characteristics, eight theoretical propositions are suggested to be tested empirically that can generate a better understanding on the mental models of entrepreneurs.

Theoretical / methodological contributions: The review of literature presented, and to a greater degree the propositions raised from this, reveal a series of research gaps and points that need to be deepened in empirical studies to develop a better understanding about how cognitive characteristics interfere in the identification and exploration of entrepreneurial opportunities.

Keywords: Entrepreneurial Opportunities. Entrepreneurial Cognition. Mental Models.

\section{COGNICIÓN EMPRENDEDORA: ELEMENTOS COGNITIVOS} QUE INFLUENCIAN LA EXPLOTACIÓN DE OPORTUNIDADES

\section{Resumen}

Objetivo del estudio: Presentar una amplia revisión de literatura sobre los elementos cognitivos que influencian los modelos mentales de emprendedores en la explotación de oportunidades.

Metodología / abordaje: Los procedimientos metodológicos utilizados en esta investigación bibliográfica se dividieron en: 1 . Formulación de la pregunta de investigación, 2. Ubicación de los estudios, 3. Selección y evaluación de los estudios, 4. Análisis y síntesis y 5 . Informe de resultados. La búsqueda de los estudios resultó en 87 artículos identificados. En la etapa de selección y evaluación, 36 artículos fueron excluidos debido a la falta de adherencia al tema deseado. Con 51 artículos seleccionados, se realizó una lectura cuidadosa de los documentos. Finalmente, los autores realizaron la revisión y análisis presentados en los resultados.

Originalidad / Relevancia: Hay una carencia de estudios sobre cómo variaciones cognitivas moldean las percepciones de los emprendedores sobre oportunidades. El estudio evidencia la diversidad de lagunas de investigación en cognición emprendedora. Principales resultados: El artículo presenta diez características cognitivas que soportan sus modelos mentales e influencian el proceso de explotación de oportunidades. A partir de los análisis de estas características, se sugieren ocho proposiciones a ser probadas empíricamente que pueden generar un mejor entendimiento sobre los modelos mentales de emprendedores.

Contribuciones teóricas / metodológicas: La revisión de literatura presentada, y en mayor grado las proposiciones planteadas a partir de ésta, revela una serie de lagunas de investigación y puntos que carecen de profundización para desarrollar un mejor entendimiento sobre cómo las características cognitivas interfieren en la explotación de oportunidades.

Palabras clave: Oportunidades emprendedoras. Cognición Emprendedora. Modelos mentales.

American Psychological Association (APA)

Behling, G., \& Lenzi, F. (2020). Cognição empreendedora: elementos cognitivos que influenciam a exploração de oportunidades. Iberoamerican Journal of Strategic Management (IJSM), 19(1), 170-199. https://doi.org/10.5585/riae.v19i1.17102. 


\section{Introdução}

Novos empreendimentos geram riqueza para as nações, elevam a dinamicidade da economia e contribuem para o bem-estar social por meio da inovação em produtos e serviços que satisfazem necessidades humanas. Estes benefícios denotam a relevância da atividade empreendedora como propulsora do desenvolvimento socioeconômico e tal reconhecimento fez com que o empreendedorismo ganhasse importância em diversas esferas, dentre as quais o âmbito acadêmico, onde se fortaleceu como um campo de pesquisas bastante frutífero.

Ao desenvolver inovações para atender necessidades dos clientes, empreendedores estimulam o desenvolvimento econômico e melhoram a qualidade de vida da sociedade (Pryor, Webb, Ireland \& Ketchen, 2016). Em um mundo extremamente complexo, dinâmico e com incerteza crescente, agir de forma empreendedora torna-se cada vez mais um atributo essencial para a sobrevivência das organizações (Shepherd, Williams \& Patzelt, 2015) e isso exige indivíduos motivados a agir em busca de oportunidades empresariais promissoras (Wood, Mckelvie \& Haynie, 2014).

Assume-se aqui o conceito de oportunidade empreendedora como a possibilidade de explorar uma necessidade do mercado por meio de uma combinação criativa de recursos com o intuito de gerar valor superior (Ardichvili, Cardozo \& Ray, 2003). A exploração de oportunidades é um dos aspectos centrais do estudo do empreendedorismo (Baron \& Ward, 2004; Baron, 2006; Shepherd et al., 2015). Compreender como e por quem as oportunidades empresariais são descobertas, avaliadas e exploradas, ocupa espaço relevante no diálogo acadêmico, e é objetivo comum dos estudiosos do empreendedorismo (Dimov, 2011), visto que a criação de um novo negócio está intrinsicamente ligada ao reconhecimento de uma oportunidade que um empreendedor acredita ter potencial para gerar resultado econômico.

Empreendedores utilizam uma grande quantidade de informações exógenas das mais diversas fontes de dados no processo de exploração de oportunidades. Contudo, é a interpretação dessas informações, em última instância, que importa. Adotando uma perspectiva em primeira pessoa, tais interpretações permitem aos indivíduos discernir o significado dos dados, traçar um conjunto de ações subsequentes e projetar os prováveis resultados a serem colhidos com uma oportunidade (Wood et al., 2014).

Esse é um processo que deriva, em parte, das estruturas cognitivas dos indivíduos desenvolvidas através de sua experiência de vida anterior. Tais estruturas servem para organizar informações armazenadas na memória e são empregadas como "modelos", os quais permitem que alguns indivíduos, em particular, percebam conexões entre pontos aparentemente não relacionados para as demais pessoas. Esses modelos fornecem a base cognitiva necessária para "conectar os pontos" e reconhecer novas oportunidades de negócios, o que pode ser a razão pela qual algumas pessoas específicas percebem as oportunidades (Baron, 2006).

Cada indivíduo carrega consigo um conjunto de modelos mentais que refletem a sua experiência em todas as esferas da vida (Chapman \& Ferfolja, 2001). Neste estudo, adota-se o conceito de Dhanaraj 
e Khanna (2011) que define o modelo mental como uma orientação cognitiva que determina como indivíduos interpretam contextos e agem a partir dessa interpretação. Assim, novos insights podem não ser colocados em prática por conflitar com imagens internas profundamente arraigadas sobre como o mundo funciona, visto que essas imagens limitam as pessoas a modos familiares de pensar e agir (Senge, 2013), inclusive em se tratando de boas ideias de negócio (Campos \& Muñoz, 2009).

A teoria dos modelos mentais postula que indivíduos processam informações por meio de estruturas (ou imagens) cognitivas, projetando cenários futuros. Ao deparar-se com novas informações, os indivíduos criam uma impressão, amparada por seus modelos mentais, e as categorizam com base na experiência passada vivida e aprendida. A compreensão dos elementos cognitivos, que moldam os julgamentos a respeito de uma oportunidade, é crítica para explicar de forma crível as condições sob as quais a atividade empreendedora é mais provável de ocorrer (Wood et al., 2014).

Porém, Mitchell, Busenitz, Bird, Gaglio, McMullen, Morse e Smith (2007) afirmam haver pouco conhecimento sobre o efeito de diferentes modelos mentais nas escolhas e decisões tomadas por empreendedores frente a uma oportunidade de negócio. Wood et al. (2014) também alertam para um certo "silêncio" sobre como as variações em elementos cognitivos podem moldar as percepções dos empresários sobre oportunidades empreendedoras. Apesar de ter recebido um fluxo constante de pesquisas nos últimos anos (Wood \& Mckelvie, 2015), um melhor entendimento da maneira como os empreendedores decidem explorar oportunidades é fundamental para o avanço do conhecimento no campo do empreendedorismo (Shepherd et al., 2015).

Trabalhar sob a ótica cognitiva requer que os pesquisadores se dediquem a compreender como os empreendedores identificam ideias de novos produtos, serviços ou modelos de negócio, como eles avaliam tais oportunidades e como desenvolvem e implementam essas ideias, tomando decisões sobre mobilização de recursos, relação com investidores, consumidores e demais partes interessadas e como o ambiente interfere em suas rotinas e estratégias de ação (Grégoire et al., 2015). Neste sentido, buscando uma melhor compreensão sobre o assunto, o problema de pesquisa a ser respondido é: "quais os elementos cognitivos influenciam a exploração de oportunidades empreendedoras?". Ao passo que o objetivo deste artigo é apresentar uma revisão sistemática da literatura sobre os elementos cognitivos que suportam os modelos mentais de empreendedores, especificamente no que diz respeito à identificação e exploração de oportunidades empreendedoras, reunindo e sintetizando contribuições de diversos autores de forma a fomentar futuros estudos que averiguem essas construções teóricas na prática empreendedora.

O artigo está estruturado da seguinte forma: após essa introdução, é apresentada uma revisão bibliográfica sobre os temas "oportunidades empreendedoras", "cognição empreendedora", "modelos mentais de empreendedores". Os procedimentos metodológicos da revisão de literatura são descritos, seguindo-se da apresentação dos resultados e da discussão destes, depois da qual as considerações finais são realizadas. 


\section{Conceitos centrais do estudo}

\section{Oportunidades empreendedoras}

A exploração de novas oportunidades é a principal característica da capacidade empreendedora. Empreender passa, sobretudo, por detectar oportunidades de negócio e adaptar a empresa internamente para explorá-las de forma criativa e rentável (Teece, 2007). É a partir das oportunidades identificadas que os empreendedores criam valor em mercados a serem desenvolvidos (Fiorin, Mello \& Machado, 2010).

As oportunidades representam um fator fundamental para o campo de conhecimento do empreendedorismo, mas, apesar disso, sua definição é bastante ampla, transversal, complexa e ambígua (Aliaga-Isla \& Rialp, 2012). Shane (2000) defende que a mudança tecnológica produz bases para a criação de novos processos, produtos, mercados e formas organizacionais. Porém, antes que essas mudanças possam ser exploradas, os empreendedores precisam descobrir oportunidades sobre como utilizar as novas tecnologias.

Para Ardichvili et al. (2003), uma oportunidade é a possibilidade de atender a uma necessidade de mercado através de uma combinação criativa de recursos para entregar valor superior. Já Dutta e Crossan (2005, p. 426) definem oportunidades empreendedoras como "um conjunto de condições ambientais que levam à introdução de um ou mais novos produtos ou serviços no mercado por um empresário ou por uma equipe empreendedora, quer através de um empreendimento existente ou recémcriado".

A oportunidade é "uma situação ou ambiente que apresenta um elemento novo e indica-o como sendo indutor para ações humanas e empresariais que levam a novas circunstâncias de mercado" (Costa, Machado \& Vieira, 2007, p. 78). Tratando especificamente desta relação entre oportunidade e mercado, Dimov (2011) defende que a natureza da oportunidade reflete a ideia de que um sistema econômico nunca atinge o seu pleno potencial. Seu estado natural é de desequilíbrio, sempre havendo espaço para ações que podem levá-lo mais perto desse virtual equilíbrio. Pela concepção sociológica dos mercados, a oportunidade pode ser vista como um continuum que parte de um produto da imaginação do empreendedor, que pretende ocupar um nicho de mercado, para se tornar um conjunto organizado de atividades de troca autossustentável (Dimov, 2011).

Na mesma ótica, Boszczowski e Teixeira (2012, p. 153) afirmam que "oportunidades são inerentes às falhas de mercado e apresentam possibilidade de melhoria do bem-estar social". Assim, segundo as autoras, são falhas de mercado que proporcionam oportunidades para gerar valor econômico e, simultaneamente, reduzir problemas ambientais e promover o desenvolvimento social.

Oportunidades empreendedoras são situações geradas pela ação empreendedora nas quais novos bens, serviços, matérias-primas e métodos organizacionais são introduzidos e vendidos por um valor maior do que o seu custo de produção (Hisrich, Peters \& Shepherd, 2014). 
A partir dos conceitos apresentados, podem-se definir oportunidades empreendedoras como o arranjo de um conjunto de recursos e/ou atividades, criado para explorar uma falha de mercado, gerada por mudanças e/ou tendências ambientais, de forma a gerar valor econômico e promover o bem-estar social.

No cerne do esforço da criação de um novo negócio está o reconhecimento de uma oportunidade que um empreendedor acredita ter potencial para produzir riqueza e que, portanto, vale a pena perseguila (Hsieh \& Kelley, 2016). Esse reconhecimento, segundo Baron (2006), depende, em partes, das estruturas cognitivas dos indivíduos desenvolvidas através de sua experiência de vida anterior. Tais estruturas servem para organizar informações armazenadas na memória e que são empregadas como "modelos", os quais permitem que alguns indivíduos em particular percebam conexões entre pontos aparentemente não relacionados para os demais. $\mathrm{O}$ autor defende que esses modelos fornecem a base cognitiva necessária para "conectar os pontos" e reconhecer novas oportunidades de negócios. Essa, de acordo com Baron (2006), pode ser a razão pela qual algumas pessoas específicas percebem oportunidades e outras não: possuir estruturas cognitivas que lhes permitem fazê-lo.

O julgamento de um empreendedor sobre o potencial de geração de valor de uma oportunidade é uma interpretação subjetiva e influenciada por sua intuição, experiências prévias e pela capacidade de traçar paralelos de causa e efeito, dentre outros elementos cognitivos (Wood et al., 2014). De um ponto de vista cognitivo, segundo Hsieh e Kelley (2016), as oportunidades emergem de um padrão complexo de condições mutáveis do ambiente e os empreendedores empregam seus quadros cognitivos para estabelecer conexões entre as mudanças do ambiente e as novas possibilidades de atender a essas demandas. Constatações como essas sugerem a cognição como uma lente relevante para compreensão do processo de identificação e exploração de oportunidades empreendedoras.

\section{Cognição empreendedora}

Empregando conceitos da psicologia cognitiva e associando-os aos estudos de oportunidades empreendedoras, Mitchell, Busenitz, Lant, McDougall, Morse e Smith (2002) cunharam o termo cognição empreendedora e o definiram como estruturas de conhecimento empregadas na avaliação, julgamento e tomada de decisões sobre oportunidades de negócio. Para Mitchell et al. (2007), a pesquisa sobre cognição empreendedora é cada vez mais reconhecida como uma perspectiva crítica e eficaz para a compreensão de fenômenos ligados ao empreendedorismo. Busca entender, principalmente, como os empreendedores raciocinam e se comportam de forma a criar valor e riqueza ao identificar e explorar oportunidades de negócio.

Armstrong, Cools e Sadler-Smith (2012) consideram os estilos cognitivos um fator fundamental e determinante do comportamento individual e organizacional, exercendo, portanto, forte influência sobre as práticas empresariais. Segundo Yang e Zhang (2015), por mais que as decisões empresariais sejam baseadas em informações do ambiente, grande parte do processo decisório é cognitivo, 
especialmente em condições de risco como as enfrentadas pelos empreendedores frente a uma oportunidade de negócio. Assim, de acordo Wood e Mckelvie (2015), a perspectiva da cognição empreendedora examina aspectos relevantes da cognição no processo empreendedor, se concentrando na identificação de estruturas de conhecimento que os empreendedores utilizam para fazer avaliações, julgamentos ou decisões, envolvendo principalmente a avaliação de oportunidades e a criação de novos empreendimentos.

Pesquisadores do campo da cognição empreendedora têm buscado entender de que forma os processos cognitivos inibem ambiguidades e incertezas inerentes ao processo empreendedor (Dew, Grichnik, Mayer-Haug, Read \& Brinckmann, 2015). Para Cortez, Ferreira, Ferreira e Araújo (2016), a memória, a experiência acumulada, o conhecimento e as habilidades específicas sobre determinada área, entre outros aspectos, influenciam a cognição. Reconhecer, segundo os autores, o que está na base dos pensamentos é capaz de tornar mais completo o entendimento das diversas variáveis envolvidas na atividade empreendedora.

Nesse sentido, o pensamento empreendedor está associado ao uso extensivo de heurísticas ou simplificações que os indivíduos utilizam para tomar de decisões estratégicas complexas, sobretudo, em circunstâncias nas quais a informação é incompleta ou imprecisa (Westhead, Ucbasaran \& Wright, 2005). Nesses casos, segundo Chermack (2003), as pessoas empregam seus modelos mentais, que agem como simplificadores, permitindo a tomada de decisão mesmo sem a compreensão completa do fenômeno em questão. Wood e McKelvie (2015) apontam uma convergência dos pesquisadores de empreendedorismo em torno da ideia de que empreendedores criam "modelos mentais" para representar circunstâncias do ambiente, dentre as quais as oportunidades e as previsões sobre a atratividade dessas oportunidades com base nas imagens construídas. No próximo tópico, os modelos mentais serão conceituados e suas características e processos pelos quais são desenvolvidos, apresentados.

\section{Modelos mentais de empreendedores}

A noção de que empreendedores desenvolvem cópias mentais de objetos e situações do mundo real tem uma longa história na filosofia, que remonta à Grécia Antiga (Badke-Schaub, Neumann, Lauche \& Mohammed, 2007). Entretanto, atribui-se a Kenneth Craik, em 1943, a definição moderna dos modelos mentais como uma representação simbólica, ou um "modelo em pequena escala" da realidade, na qual o ser humano traduz ou interpreta elementos do ambiente. Essa simulação do mundo, ou representação dinâmica da realidade, influencia as atitudes possíveis em situações vivenciadas (Park \& Gittelman, 1995; Westbrook, 2006; Badke-Schaub et al., 2007; De Toni \& Milan, 2008; Dhanaraj \& Khanna, 2011).

O termo se disseminou de forma consistente a partir de duas obras, ambas intituladas "Mental Models" e publicadas no ano de 1983. A primeira delas, de Dedre Gentner e Albert L. Stevens, é uma coletânea de contribuições e conceitos extraídos de um seminário sobre o tema. Já a segunda obra, de 
autoria de Philip Johnson-Laird, tem como objetivo explicar o raciocínio dedutivo e a compreensão de textos (Borges, 1997).

Segundo Senge (1992), os modelos mentais afetam o que se vê. Assim, duas pessoas com diferentes modelos mentais podem observar o mesmo fenômeno, descrevendo-o de forma diferente porque assim o perceberam. Peter M. Senge é conhecido por divulgar amplamente o conceito dos modelos mentais em seu livro intitulado "A quinta disciplina" e publicado originalmente, em 1990, nos Estados Unidos. Para Senge (2013), modelos mentais são imagens internas profundamente arraigadas sobre o funcionamento do mundo, que limitam a forma de pensar e agir. Podem ser generalizações simples ou teorias complexas, são ativos e moldam nossa forma de agir.

Chermack (2003) afirma que os indivíduos constroem modelos mentais para nos convencermos de que entendemos os diversos fenômenos com os quais nos deparamos e, ao fazê-lo, nos permitimos "funcionar" em situações nas quais não possuímos a compreensão completa. Desta forma, os modelos mentais incorporam nossos preconceitos, valores, aprendizados, experiências e crenças sobre como o mundo funciona.

Um modelo mental é uma teoria pessoal de como as coisas funcionam, formada por fatores relevantes percebidos e as diversas relações entre esses fatores que, em conjunto, configuram uma forma de interpretar as entradas sensoriais. São roteiros simplificados da vida e afetam a forma como as pessoas interpretam situações e guiam o seu comportamento, incluindo a estruturação de problemas, a coleta e o processamento de informações, a avaliação, a escolha, a implementação e o aprendizado (Brønn \& Brønn, 2003).

A ideia básica em torno dos modelos mentais é que os seres humanos constroem modelos internos do funcionamento do mundo, ou simplificações deste. Tais modelos permitem a integração de novas informações em situações cotidianas e a realização de previsões com pouco esforço mental. Os modelos mentais refletem nossa capacidade de categorizar o que sabemos e organizar o conhecimento (BadkeSchaub et al., 2007).

Os modelos mentais são, portanto, formas de subjetivação que refletem como os indivíduos sentem, percebem, imaginam, compreendem, dão significado, criam conviç̧ões e se comportam. Os vieses e as suposições dos modelos mentais são adquiridos por meio de experiências passadas e representam uma visão ampla do mundo. Influenciam a forma como o sujeito percebe o contexto, como processa as informações e, consequentemente, como agirá frente a situação enfrentada (De Toni \& Milan, 2008). Dhanaraj e Khanna (2011, p. 692) defendem que o modelo mental é “[...] uma orientação cognitiva distinta que determina como interpretamos contextos, que, por sua vez, controlam comportamentos".

A teoria dos modelos mentais postula que os indivíduos processam informações por meio da construção de modelos cognitivos (ou imagens) da situação atual e projetam esses modelos para possíveis cenários futuros. Ao encontrar novas informações, sejam elas pessoas, eventos ou situações, 
os indivíduos criam uma impressão (ou o modelo mental) e categorizam essa nova informação a partir da experiência vivida e aprendida (Wood et al., 2014).

Dada a incerteza associada à atividade empresarial, é recorrente a necessidade de tomar decisões rápidas nas quais frequentemente não se dispõem da informação necessária para tanto. Nesse caso, o modo de pensamento heurístico, apoiado nos modelos mentais, é utilizado com frequência para aumentar a velocidade de uma decisão e a eficácia da resposta (Shepherd et al., 2015). Para Pryor et al. (2016), as heurísticas ou vieses cognitivos são atalhos de processamento de informações que reduzem o tempo e o esforço dos indivíduos para avaliar informações e tomar decisões, ajudando a reduzir a incerteza e a guiar comportamentos. Na medida em que a tipicidade de uma situação aumenta, os indivíduos recorrem mais às heurísticas para se comportar nessas situações. Como simplificações, os modelos mentais não necessariamente representam precisamente o mundo, mas a sua simplicidade os torna úteis na medida em que uma pessoa compreenda e aja rapidamente mesmo em situações desconhecidas (Badke-Schaub et al., 2007).

Para Milan, De Toni, Dorion e Schuler (2011), se cada ser humano é único e cada negócio também, é difícil haver um modelo mental ideal. O que se pode conjeturar é que existem formas de pensar e agir que contribuam para o direcionamento de melhores resultados nas organizações. Nesse sentido, busca-se neste estudo, por meio de uma revisão sistemática da literatura, compreender os principais elementos cognitivos que suportam os modelos mentais de empreendedores, essencialmente no que diz respeito à identificação e exploração de oportunidades empreendedoras. Nos tópicos subsequentes, são apresentados os processos de busca e seleção das obras utilizadas bem como as contribuições oriundas desta revisão bibliográfica.

\section{Procedimentos metodológicos}

Os procedimentos metodológicos empregados nesta revisão de literatura foram divididos em cinco etapas, conforme proposto por Denyer e Tranfield (2009): 1. Formulação da questão de pesquisa; 2. Localização dos estudos; 3. Seleção e avaliação dos estudos; 4. Análises e síntese; e 5. Relato dos resultados. Para os autores, a primeira decisão ao preparar uma revisão sistemática de literatura, assim como em qualquer pesquisa, é definir uma clara questão problema. Neste estudo, a questão norteadora é: quais elementos cognitivos influenciam a exploração de oportunidades empreendedoras? O segundo passo em uma revisão sistemática é localizar os estudos relevantes para responder à questão de pesquisa. Para localizar os estudos revisados, os passos realizados devem ser relatados em detalhes, possibilitando a replicação do estudo (Denyer \& Tranfield, 2009). Para essa etapa, foram definidas as bases de dados EBSCOhost ${ }^{\circledR}$ e Portal de Periódicos CAPES. Os termos de busca empregados foram: oportunidades empreendedoras, oportunidades, cognição empreendedora, modelos mentais, heurísticas, representações mentais, elementos cognitivos e metacognição. Os termos foram buscados nas línguas portuguesa e inglesa nos títulos, palavras-chave ou resumos, utilizando-se o operador booleano AND para que, ao 
menos, dois dos termos de busca estivessem presentes nas obras. Definiu-se a data de publicação igual ou posterior ao ano 2000. Esse procedimento inicial resultou em 87 artigos. De acordo com Denyer e Tranfield (2009), o procedimento seguinte é definir o conjunto de critérios para selecionar os estudos relevantes para a questão de pesquisa, deixando claras as regras de inclusão ou exclusão dos textos. Nesta etapa do estudo, os resumos e palavras-chave dos artigos identificados foram lidos para verificar sua aderência aos objetivos deste estudo e a decisão de exclusão pautou-se nos seguintes critérios: c1) exclusão dos artigos que não tratem especificamente de oportunidades empreendedoras ou do processo empreendedor; e c2) exclusão dos artigos que não citem especificamente elementos cognitivos empregados na análise de oportunidades empreendedoras ou do processo empreendedor. Trinta e seis artigos foram excluídos devido ao não atendimento de, pelo menos, um desses dois critérios, restando 51 textos para etapa seguinte. Todos os artigos que compuseram essa amostra são apresentados na

Tabela 1, indicando ano de publicação, autoria e periódico.

Tabela 1 - Amostra da revisão de literatura

\begin{tabular}{|c|c|c|c|}
\hline Ano & Autoria & Periódico & Incluso no Relato (x) \\
\hline 2000 & Shane & Organization science & $\mathrm{X}$ \\
\hline 2002 & Mitchell et al. & Entrepreneurship theory and practice & \\
\hline 2003 & Ardichvili et al. & Journal of Business venturing & \\
\hline 2004 & Baron \& Ward & Entrepreneurship Theory and Practice & \\
\hline 2004 & Ward & Journal of business venturing & $\mathrm{X}$ \\
\hline 2005 & Dutta \& Crossan & Entrepreneurship Theory and Practice & \\
\hline 2005 & Westhead et al. & International Small Business Journal & $\mathrm{X}$ \\
\hline 2006 & Baron & Academy of management perspectives & $\mathrm{X}$ \\
\hline 2006 & De Carolis \& Saparito & Entrepreneurship theory and practice & $\mathrm{X}$ \\
\hline 2006 & Westbrook & Journal of Information Science & \\
\hline 2007 & Costa et al. & Desenvolvimento em questão & \\
\hline 2007 & Krueger & Entrepreneurship theory and practice & $\mathrm{X}$ \\
\hline 2007 & Mitchell et al. & Entrepreneurship theory and practice & \\
\hline 2008 & De Toni \& Milan & READ-Revista Eletrônica de Administração & \\
\hline 2008 & Mitchell et al. & Strategic Entrepreneurship Journal & $\mathrm{X}$ \\
\hline 2008 & Moreno & International journal of Entrepreneurship & \\
\hline 2009 & Bryant & Journal of Business Venturing & $\mathrm{X}$ \\
\hline 2009 & Campos \& Muñoz & Revista Brasileira de Gestão de Negócios & \\
\hline 2009 & Haynie \& Shepherd & Entrepreneurship Theory and Practice & $\mathrm{X}$ \\
\hline 2009 & Hmieleski \& Baron & Academy of management Journal & $\mathrm{X}$ \\
\hline 2010 & Alvarez \& Barney & Academy of Management annals & $\mathrm{X}$ \\
\hline 2010 & Cassar & Strategic Management Journal & $\mathrm{X}$ \\
\hline 2010 & Fillis \& Rentschler & Journal of Enterprising Culture & $\mathrm{X}$ \\
\hline 2010 & Fiorin et al. & Revista de Administração da UFSM & \\
\hline 2010 & Ucbasaran et al. & Journal of Business Venturing & $\mathrm{X}$ \\
\hline 2011 & Dimov & Entrepreneurship Theory and Practice & \\
\hline 2011 & Milan et al. & Revista Eletrônica de Gestão Organizacional & $\mathrm{X}$ \\
\hline 2011 & Sánchez et al. & Psicothema & $\mathrm{X}$ \\
\hline 2011 & Teixeira et al. & REGE Revista de Gestão & \\
\hline 2012 & Aliaga-Isla \& Rialp & Latin American Business Review & \\
\hline 2012 & Armstrong et al. & $\begin{array}{l}\text { International Journal of Management } \\
\text { Reviews }\end{array}$ & \\
\hline 2012 & Boszczowski \& Teixeira & Revista Economia \& Gestão & \\
\hline 2012 & Hogarth \& Karelaia & Organization Science & $\mathrm{X}$ \\
\hline 2012 & Tang et al. & Journal of Business Venturing & \\
\hline 2013 & Arentz et al. & Small Business Economics & \\
\hline
\end{tabular}




\begin{tabular}{|c|l|l|c|}
\hline 2013 & Garud \& Giuliani & Academy of Management Review & \\
\hline 2013 & Riquelme & Journal of Enterprising Culture & X \\
\hline 2014 & Wood et al. & $\begin{array}{l}\text { International Journal of Management } \\
\text { Reviews }\end{array}$ & \\
\hline 2015 & Cacciotti \& Hayton & $\begin{array}{l}\text { International Journal of Management } \\
\text { Reviews }\end{array}$ & \\
\hline 2015 & Dew et al. & $\begin{array}{l}\text { International Journal of Management } \\
\text { Reviews }\end{array}$ & \\
\hline 2015 & Grégoire et al. & Journal of Management Reviews & $\mathrm{X}$ \\
\hline 2015 & Shepherd et al. & Journal of management & $\mathrm{X}$ \\
\hline 2015 & Wood \& McKelvie & $\begin{array}{l}\text { International Journal of Management } \\
\text { Reviews }\end{array}$ & \\
\hline 2015 & Yang \& Zhang & Journal of Developmental Entrepreneurship & $\mathrm{X}$ \\
\hline 2016 & Cortez et al. & $\begin{array}{l}\text { Revista de Empreendedorismo e Gestão de } \\
\text { Pequenas Empresas }\end{array}$ & $\mathrm{X}$ \\
\hline 2016 & Hsieh \& Kelley & Journal of Small Business Management & $\mathrm{X}$ \\
\hline 2016 & Martin \& Wilson & International Small Business Journal & $\mathrm{X}$ \\
\hline 2016 & Marvel et al. & Entrepreneurship Theory and Practice & \\
\hline 2016 & Pryor et al. & Strategic Entrepreneurship Journal & \\
\hline 2016 & Beugré & $\begin{array}{l}\text { Intelligence, Sustainability, and Strategic } \\
\text { Issues in Management: Current Topics in } \\
\text { Management }\end{array}$ & $\begin{array}{l}\text { Social Behavior and Personality: an } \\
\text { international journal }\end{array}$ \\
\hline 2017 & Bao et al. & & \\
\hline
\end{tabular}

Fonte: Elaborado pelos autores.

Esses cinquenta e um textos passaram pelo processo de análise e síntese (Denyer \& Tranfield, 2009), no qual foram examinados minuciosamente em seu conteúdo para estabelecer as relações entre os elementos cognitivos e o processo de identificação e exploração de oportunidades empreendedoras. Importante ressaltar que não foram utilizados nessa etapa softwares ou ferramentas para análise de conteúdo. Esta se deu por meio da leitura detalhada pelos pesquisadores e da extração de trechos relevantes. Após a leitura completa dos textos e respectiva análise, vinte e seis artigos não apresentaram categorias ou elementos cognitivos específicos que influenciam o processo de exploração de oportunidades, embora tratassem do tema de maneira genérica. Os vinte e cinco textos restantes, identificados na Tabela 1 e marcados na coluna 3, apresentavam especificamente elementos cognitivos e foram inclusos na formulação do relato, etapa final da revisão sistemática de literatura (Denyer \& Tranfield, 2009) e que é apresentado na seção seguinte deste artigo. A Figura 1 resume os procedimentos da revisão sistemática de literatura. 
Figura 1 - Procedimentos da revisão de literatura

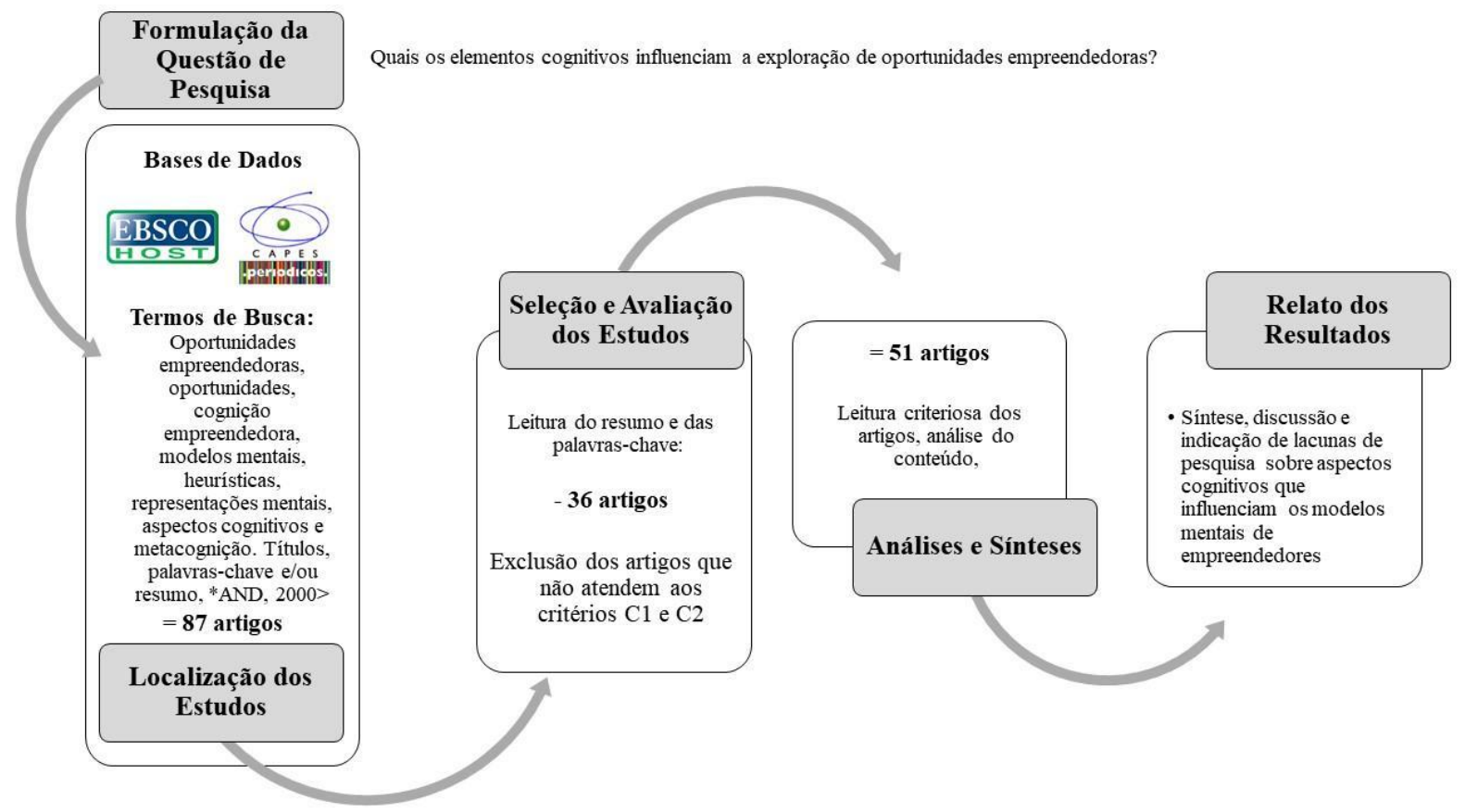

Fonte: Elaborado pelos autores.

\section{Discussão dos resultados}

Os procedimentos de revisão da literatura, previamente apresentados, resultaram em um conjunto de dez elementos cognitivos de empreendedores que suportam seus modelos mentais e influenciam o processo de identificação e exploração de oportunidades empreendedoras. Todas essas categorias foram descritas e discutidas pelos autores nos vinte e cinco artigos apresentados na Tabela 1 e que compuseram a discussão dos resultados. Os dez elementos são apresentados nos tópicos que seguem, na seguinte estrutura: a) autores que o abordam, b) seu conceito, c) sua relação com a identificação e exploração de oportunidades e com os demais elementos cognitivos e d) lacunas de pesquisa a respeito do elemento cognitivo.

\section{A experiência prévia}

Nos artigos revisados, uma série de autores atribui relevância significativa à experiência prévia nas imagens mentais criadas por empreendedores para embasar suas ações e decisões futuras (Westhead et al. 2005; Baron, 2006; Krueger, 2007; Wood \& Mckelvie, 2015; Shepherd et al., 2015; Hsieh \& Kelley, 2016; Pryor et al., 2016).

Define-se essa característica como a experiência anterior com a propriedade de empresas e os empreendedores podem ser divididos em três grupos: empreendedores iniciais, que nunca tiveram experiência anterior como sócios de empresas privadas e atualmente possuem cotas em uma empresa nova, comprada ou herdada; empreendedores seriais, indivíduos que venderam ou fecharam um negócio no qual possuíam participação no capital e que, no momento, possuem uma cota em uma empresa nova, 
comprada ou herdada; e empreendedores de portfólio, indivíduos que possuem participação em dois ou mais negócios independentes de forma simultânea (Westhead et al., 2005). Além da experiência com a propriedade de empresas, Marvel, Davis e Sproul (2016) argumentam que o trabalho anterior em uma indústria específica e o número de cargos de gestão, previamente ocupados por um indivíduo, podem contribuir para a atividade empreendedora futura.

Embora o campo de estudos precise avançar no entendimento de como a experiência prévia de um empreendedor impacta na sua tomada de decisão, estudos têm demonstrado que avaliações e decisões relacionadas às oportunidades de negócio são diferentes entre empreendedores experientes e novatos (Shepherd et al., 2015).

Dentre os principais benefícios gerados pela experiência prévia, Westhead et al. (2005) citam um conjunto de habilidades gerenciais e técnicas, além de uma rede de contatos a ser explorada em empreendimentos subsequentes.

Empreendedores experientes também utilizam e processam novas informações de forma mais eficaz que os inexperientes. Estes, muitas vezes, são sufocados pelo excesso de informação e não possuem um quadro de referência para priorizar o que é relevante. Empreendedores experientes organizam e estruturam uma base de conhecimento de maneira mais eficiente que os novatos (Westhead et al., 2005; Krueger, 2007). É plausível, portanto, que empreendedores experientes possuam estruturas cognitivas mais ricas e bem desenvolvidas que lhe sejam úteis na percepção de eventos e na consequente identificação de novas oportunidades (Baron, 2006).

Milan et al. (2011) afirmam que a experiência anterior como empreendedor tende a aumentar as chances de sucesso de um novo negócio. Segundo Wood e McKelvie (2015), os indivíduos usam sua experiência e informações prévias para desenvolver uma imagem mental da oportunidade e usá-la para avaliar a atratividade e a viabilidade de perseguir a oportunidade percebida. Nesse sentido, o estudo de Hsieh e Kelley (2016) demonstra que indivíduos que sabem como funciona uma indústria e compreendem aspectos como relações com fornecedores e características dos concorrentes estão mais bem posicionados para reconhecer oportunidades relevantes. A experiência os torna mais sensíveis a desequilíbrios macro e microeconômicos como mudanças políticas, de tecnologia ou situações que gerem ineficiências de mercado. Assim, empreendedores mais experientes possuem uma maior capacidade cognitiva para entender as implicações das mudanças e perceber o potencial comercial subjacente.

A experiência pode, contudo, acarretar pontos negativos: o sucesso anterior pode elevar a autoestima de forma demasiada e o excesso de confiança dos empreendedores. Além disso, estes podem tentar repetir receitas de sucesso, passado em circunstâncias atuais, o que pode se tornar negativo (Westhead et al., 2005).

Os estudos revisados convergem para lacunas de pesquisa em relação ao papel específico da experiência prévia sobre os modelos mentais de empreendedores e como esses evoluem e tornam-se mais complexos ao longo do tempo. Este conhecimento pode significar um ponto de inflexão importante 181 
no estudo das oportunidades empreendedoras (Westhead et al., 2005; Baron, 2006; Krueger, 2007; Shepherd et al., 2015). Krueger (2007) salienta que compreender o empreendedorismo é entender como indivíduos se tornam empreendedores experientes e isso requer avançar a um nível cognitivo mais profundo, explorando como as estruturas de conhecimento evoluem e como os empreendedores experientes estruturam e empregam seu conhecimento, tácito ou explícito, para explorar oportunidades.

\section{O domínio de conhecimento}

Outra característica cognitiva apontada como capaz de influenciar os modelos mentais de empreendedores é o domínio de conhecimento (Shane, 2000; Ward, 2004; Baron, 2006; Alvarez \& Barney, 2010; Milan et al., 2011; Marvel et al., 2016; Wood et al., 2014). Este pode ser definido como a compreensão de princípios, fatos, processos e as interações entre eles. $\mathrm{O}$ conhecimento tende a ser mais valioso quando é específico de um domínio particular e relacionado a atividades empresariais específicas (Marvel et al., 2016).

Segundo Milan et al. (2011), o domínio de conhecimento envolve noções técnicas (do produto, serviço, processo fabril e/ou operações) e conhecimento de aspectos do ambiente que facilita a identificação de oportunidades e ameaças, bem como as exigências do mercado.

Shane (2000) argumenta que o conhecimento gerado através da educação e da experiência, principalmente o conhecimento relacionado às necessidades dos clientes e a familiaridade com os problemas por eles enfrentados, torna algumas pessoas mais propensas do que outras a descobrir oportunidades.

Na visão de Wood et al. (2014), quanto maior o grau em que o conhecimento necessário, para identificar, avaliar e explorar uma oportunidade, é semelhante ao conhecimento que o empreendedor já detém, maior será a atenção e compreensão das oportunidades de mercado por parte do empreendedor e mais atraente a oportunidade parecerá ao empresário, visto que, segundo Alvarez e Barney (2010), os empreendedores combinam o conhecimento e a informação que já detém a novas informações e conhecimento coletado. Marvel et al. (2016) destacam que vínculos e alianças entre empresas geram uma série de vantagens, associada a geração de conhecimento compartilhado, e mais benefícios do que o conhecimento desenvolvido individualmente.

O conhecimento de áreas alheias ao negócio em específico, contudo, pode ser proveitoso no processo de identificação de oportunidades. Ward (2004) aponta a existência de uma variedade de processos pelos quais empreendedores modificam, estendem ou transformam seu conhecimento. Em especial, o autor destaca a combinação conceitual, definida como um processo pelo qual ideias ou conceitos previamente separados são mentalmente fundidos. Na visão do autor, essa é uma característica relevante para empreendedores em busca de novas ideias a serem exploradas comercialmente. Outro processo criativo, destacado por Ward (2004), é o raciocínio analógico que tem como objetivo aplicar conhecimentos de um domínio para auxiliar a compreensão ou o desenvolvimento de ideias em outro. 
O campo de estudos necessita de aprofundamento sobre até que ponto o domínio do conhecimento é relevante para a exploração de novas oportunidades (Shane, 2000; Milan et al., 2011; Wood et al., 2014). Embora existam evidências de que o conhecimento prévio específico em determinado domínio pode aumentar as possibilidades de identificar novas oportunidades, qual é a importância do novo conhecimento divergente à área de domínio nesse processo? Ward (2004) e Baron (2006), por exemplo, defendem que a associação de domínios não relacionados pode suscitar novas oportunidades empreendedoras. Outro aspecto que requer maior explicação é o processo pelo qual o novo conhecimento é absorvido e empregado por empreendedores na identificação e exploração de oportunidades e estudos sobre capacidade absortiva individual que podem contribuir de forma significativa.

\section{Fracasso anterior}

O fracasso empresarial anterior influencia a futura tomada de decisões sobre a criação de novos negócios (Mitchell; Mitchell \& Smith, 2008; Ucbasaran et al., 2010; Wood et al., 2014). O fracasso pode ser definido como uma situação em que uma empresa apresenta performance abaixo do esperado de forma que a continuidade das atividades é comprometida. Não necessariamente a empresa precisa entrar em falência ou liquidação, mas a operação é abortada por não atingir o patamar de desempenho previsto pelo empreendedor. De todo modo, a falha empresarial é uma experiência emocional traumática que afeta julgamentos e decisões futuras, podendo tornar o empreendedor mais conservador (Wood et al., 2014).

Segundo Mitchell et al. (2008), boa parte dos empreendedores experimentou falhas em algum momento de sua trajetória empresarial e a forma de enquadrar o fracasso pode fazer com que muitos destes empreendedores não se envolvam em novas tentativas de explorar oportunidades. Segundo os autores, em alguns casos, os empreendedores interpretam o fracasso como sinais de que não existem oportunidades no mercado que exploravam. Outras vezes, porém, essas falhas podem ser interpretadas como fontes potenciais de novas oportunidades.

Mais do que a falha em si, Mitchell et al. (2008) destacam a maneira como os empreendedores lidam com o fracasso anterior. Enquanto para alguns o insucesso limita novas intenções empreendedoras, para outros indivíduos parece um sinal para continuar a perseguir seus objetivos.

Os autores apresentam um construto denominado "new transaction commitment mindset" que representa a medida em que um empreendedor está psicologicamente comprometido a engajar-se em novas interações socioeconômicas. Indivíduos que não possuem essa característica, segundo os autores, são menos propensos a voltar a empreender após uma experiência fracassada. A mentalidade do empreendedor age como um moderador entre um evento de falha e a decisão de continuar empreendendo. 
Eventos negativos anteriores levam algumas pessoas a imaginar-se em situações de falhas futuras, acreditando que, se aconteceu no passado, pode acontecer novamente (Ucbasaran et al., 2010). Pessoas com elevado medo do fracasso percebem-no como um evento inaceitável que carrega implicações negativas para a autoestima. Ao experimentar uma situação de insucesso, indivíduos avessos ao fracasso tornam-se relutantes em envolver-se em novas atividades empreendedoras, individualizando novas oportunidades de maneira pessimista e conservadora (Wood et al., 2014).

O contrário também é verdade, segundo Ucbasaran et al. (2010). Empreendedores que não experimentaram eventos negativos sentem-se alheios a falha, tendo motivação limitada para questionar o seu modo de pensar e o seu processo de tomada de decisão, já que produziram resultados positivos anteriormente. Esse grupo de empreendedores, segundo os autores, é mais otimista do que empreendedores iniciais.

Todavia, o fracasso anterior pode trazer contribuições importantes aos empreendedores. Para Mitchell et al. (2008), o fracasso gera aprendizado que torna o empreendedor mais bem preparado, flexível e realista na exploração de oportunidades futuras. Wood et al. (2014) também defendem o ponto de vista de que o insucesso gera aprendizados importantes e que essas lições aumentam as chances de sucesso em empreendimentos futuros.

Contudo, um melhor entendimento ainda é necessário sobre a influência do fracasso anterior em futuras iniciativas empreendedoras (Mitchell et al., 2008; Wood et al., 2014). Experiências negativas geram aprendizados importantes que aumentam as chances de sucesso em futuros empreendimentos ou tornam os empreendedores avessos ao risco, reduzindo as chances de se envolverem novamente em atividades empreendedoras?

\section{Propensão ao risco}

Desde os primeiros escritos sobre empreendedorismo, o risco sempre esteve associado à figura do empreendedor e é inerente à atividade empresarial. Diversos trabalhos recentes, selecionados nesta revisão, citam a atitude em relação ao risco como fator determinante da identificação e exploração de oportunidades, demonstrando ainda haver espaço para a discussão do tema (Fillis \& Rentschler, 2010; Yang \& Zhang, 2015; Shepherd et al., 2015; Hsieh \& Kelley, 2016).

Fillis e Rentschler (2010) definem a propensão ao risco como a disposição das pessoas em comprometer recursos significativos, de forma calculada, para explorar oportunidades e obter sucesso empresarial. Já Yang e Zhang (2015) definem os riscos do negócio como perdas potenciais associadas a uma situação de negócio particular. Hsieh e Kelley (2016), por sua vez, conceituam a propensão ao risco como a tendência de um indivíduo a assumir ou evitar o risco, decisão essa influenciada pela forma como o indivíduo avalia as condições de incerteza.

Empreendedores operam em ambientes caracterizados por altos níveis de risco, fazem julgamentos e tomam decisões sob condições de extrema incerteza. Neste cenário, o risco percebido, 
segundo Hsieh e Kelley (2016), desempenha um papel relevante na maneira como os empreendedores avaliam as oportunidades de negócios disponíveis.

Os riscos resultam de mudanças internas e externas e, portanto, os empresários precisam identificá-las e gerenciá-las para minimizar o seu potencial. O processamento de informações para reconhecimento de riscos em novos empreendimentos ocorre em dois estágios: a seleção de informações relevantes do ambiente e a avaliação dessas informações. No primeiro estágio, os empreendedores selecionam informações relevantes do ambiente, empregando ferramentas de seu sistema sensorial. Durante este processo, interagem com o ambiente, percebem e codificam as informações para atribuirlhe significado. As informações sensoriais são armazenadas para que processos inconscientes as analisem e determinem se a entrada deve ser armazenada na memória de trabalho, caso seja relevante, ou descartada, caso seja irrelevante (Yang \& Zhang, 2015).

Já no estágio seguinte, os empreendedores avaliam o valor da informação, fazendo o seu julgamento. A nova informação é comparada com outras informações de risco armazenadas na memória. No caso de a nova informação ser semelhante a qualquer conhecimento prévio classificado de riscos, será rotulada como "risco" e o quadro já existente será reforçado. Caso contrário, a nova informação será processada a posteriori no caso de o empreendedor considera-la valiosa. Nessa situação, mais informações são recolhidas para fins de verificação. Confirmada, a nova informação será integrada ao quadro existente de risco e o quadro modificado/ampliado para processos de identificação de riscos futuros. Caso contrário, a informação torna-se inútil e é descartada (Yang \& Zhang, 2015).

A incerteza é, portanto, subjetiva, na medida em que diferentes indivíduos podem ter impressões diferentes sobre uma mesma situação (Hsieh \& Kelley, 2016). Empreendedores são heterogêneos em suas avaliações de risco, o que afeta a tomada de decisão empresarial (Shepherd et al., 2015). De maneira geral, indivíduos empreendedores são mais propensos ao risco do que os não empreendedores e, em sua maioria, são mais otimistas em suas avaliações de situações de negócios (Yang \& Zhang, 2015).

No caso de novos empreendimentos, tanto as redes sociais pessoais como as cognições dos empreendedores desempenham papéis críticos no reconhecimento do risco. Para reconhecer os riscos de um novo negócio, empreendedores coletam informações sobre riscos potenciais e os analisam de forma a fazer seu próprio julgamento de risco (Yang \& Zhang, 2015).

Hsieh e Kelley (2016) defendem haver necessidade de estudos que demonstrem como empreendedores avaliam o risco de uma oportunidade e agem para amenizá-lo. Especificamente em relação aos modelos mentais, Yang e Zhang (2015) questionam: como o uso de heurísticas e estratégias de simplificação podem levar os empreendedores a vieses cognitivos, bloqueando o fluxo de informações valiosas e limitando sua capacidade de avaliar o risco? 
Outra característica cognitiva capaz de influenciar os modelos mentais de empreendedores e, por conseguinte, a identificação de oportunidades é o excesso de confiança (De Carolis \& Saparito, 2006; Sánchez, Carballo \& Gutiérrez, 2011; Milan et al., 2011; Hogarth \& Karelaia, 2012; Shepherd et al., 2015).

O excesso de confiança pode ser definido como um viés cognitivo causado pela dificuldade em reconhecer os limites do nosso conhecimento. É uma espécie de uma superestimação de habilidades e indivíduos confiantes em excesso superestimam a probabilidade de estarem certos, ignorando novas informações e não percebendo a extensão na qual os seus planos, projeções ou estimativas são imprecisos (De Carolis \& Saparito, 2006).

Ocorre, normalmente, quando as avaliações dos indivíduos são excessivamente otimistas. Essa característica pode ser derivada de uma má metacognição ou dos vieses de confirmação ou retrospectiva. $\mathrm{O}$ viés de confirmação consiste na tendência em coletar informações e evidências que confirmem as suas crenças, dando maior peso a elas e ignorando informações dissonantes. Já o viés de retrospectiva é a tendência em interpretar eventos passados como mais previsíveis do que realmente eram, uma espécie de "eu sabia" (Sánchez et al., 2011).

Hogarth e Karelaia (2012) argumentam que indivíduos que erroneamente superestimam suas chances de sucesso, esperam acertar onde outros falham, permitindo a entrada em mercados não lucrativos. Assim, na visão dos autores, a confiança nas próprias habilidades empreendedoras determina, em grande parte, a decisão de iniciar um novo negócio e aqueles que iniciam empreendimentos, de forma geral, apresentam maior grau de confiança do que os não empreendedores.

$\mathrm{Na}$ maioria das vezes, as consequências do excesso de confiança são negativas, visto que empreendedores excessivamente confiantes podem avaliar setores industriais como atrativos apesar de informações demonstrarem o contrário e expandir seus empreendimentos mesmo com feedbacks negativos do mercado (Shepherd et al., 2015). A confiança em excesso pode fazer com que novas informações relevantes sejam ignoradas após uma decisão inicial ter sido tomada. Os indivíduos com confiança excessiva tratam suas suposições como fatos, o que pode levá-los a acreditar que determinadas situações sejam menos arriscadas do que realmente o são. Além disso, o excesso de confiança faz com que as pessoas busquem informações que suportem suas opiniões, ignorando elementos contraditórios (De Carolis \& Saparito, 2006).

Milan et al. (2011) afirmam que o empreendedor necessita ter uma autoestima equilibrada. A falta de confiança em si pode comprometer a realização do empreendimento, porém em excesso pode levar o empreendedor a subestimar as ameaças ao seu negócio.

De toda forma, alguns pontos positivos originam-se do excesso de confiança. Hogarth e Karelaia (2012) afirmam que a confiança reduz o número de oportunidades perdidas, visto que a confiança nas próprias habilidades determina em grande parte a decisão de um empreendedor iniciar um novo negócio. 
Já Shepherd et al. (2015) destacam que empresários com essa característica comportamental têm maior entusiasmo para alcançar metas, que muitos julgam inatingíveis, desencadeiam emoções positivas e promovem a resiliência empresarial frente a obstáculos.

De Carolis e Saparito (2006) apresentam algumas suposições, não testadas empiricamente, sobre o excesso de confiança na atividade empreendedora e que podem ser averiguadas para melhor elucidação do construto. Dentre as quais, destacam-se: o excesso de confiança está negativamente associado à percepção de risco; e a confiança dos empreendedores em seus contatos e redes está positivamente relacionada com o seu excesso de confiança.

\section{Otimismo}

O otimismo é outra característica pessoal capaz de influenciar os modelos mentais de empreendedores e sua percepção sobre o potencial de oportunidades de negócio (Hmieleski \& Baron, 2009; Cassar, 2010; Ucbasaran et al., 2010; Sánchez et al., 2011; Shepherd et al., 2015).

O otimismo é uma tendência a acreditar que as coisas vão dar certo (Sánchez et al., 2011). Referese à disposição em esperar resultados positivos, mesmo quando tais expectativas não são racionalmente justificadas (Shepherd et al., 2015). Ao optar por investir tempo e capital em um empreendimento, indivíduos o fazem com certa dose de expectativa de sucesso (Cassar, 2010).

Ucbasaran et al. (2010) afirmam que empreendedores são comumente descritos como indivíduos otimistas e que elevadas taxas de insucesso empresarial podem ser atribuídas a esse viés. Empreendedores em estágios iniciais da criação de seus negócios são otimistas em relação às projeções de vendas, na elaboração de planos e projeções financeiras e em relação à valorização e captação de investimentos para suas inovações (Shepherd et al., 2015). Sánchez et al. (2011) apontam que o otimismo tende a ser maior quando empreendedores têm maior compromisso emocional com os resultados de seu trabalho.

Hmieleski e Baron (2009) testaram empiricamente a relação entre otimismo do empreendedor e desempenho da organização. Os resultados, de forma geral, demonstram que o otimismo dos empreendedores se relaciona negativamente com o desempenho. Entre os motivos, apontados pelos autores, estão: o fato de indivíduos altamente otimistas traçarem expectativas irrealistas, sofrerem de excesso de confiança e desconsiderarem informações negativas a respeito do negócio, características que interferem seriamente na capacidade de julgamento e tomada de decisão. Sánchez et al. (2011) também defendem que é plausível que pessoas otimistas em nível suficiente para iniciar um empreendimento demonstrem uma tendência para o viés de excesso de confiança no sentido de subestimar o risco que enfrentam. Outro efeito negativo do otimismo é o retardamento da decisão para encerrar projetos malsucedidos (Shepherd et al., 2015).

Especificamente sobre planos e projeções financeiras, o estudo realizado por Cassar (2010) revela um ponto interessante e, de certa forma, contraditório. Nos achados do autor, a adoção de planos e 
cenários na gestão do empreendimento, em especial os de projeções financeiras, exacerba significativamente a tendência de empreendedores fazerem projeções excessivamente otimistas, o que pode estar relacionado ao viés de confirmação (Sánchez et al., 2011).

Hmieleski e Baron (2009) destacam alguns benefícios importantes do otimismo para a atividade empreendedora, dentre os quais: a maior capacidade de desenvolver redes sociais, maior resistência ao estresse prolongado e maior persistência diante de adversidades. Shepherd et al. (2015) complementam com um aumento do esforço destinado ao empreendimento.

Lacunas de pesquisa identificadas nos estudos revisados apontam para uma melhor compreensão em como se dá a relação entre otimismo (Cassar, 2010; Hmieleski \& Baron, 2009; Ucbasaran et al., 2010), excesso de confiança (De Carolis \& Saparito, 2006; Sánchez et al., 2011) e propensão ao risco (Hsieh \& Kelley, 2016).

\section{Criatividade}

A criatividade é um elemento importante do empreendedorismo tanto no processo de descoberta quanto na exploração de oportunidades (Ward, 2004; Baron, 2006, Fillis \& Rentschler, 2010; Milan et al., 2011; Martin \& Wilson, 2016). O simples fato de que o empreendedorismo, muitas vezes, resulta em algo novo, o torna intrinsicamente vinculado à criatividade humana. O quanto a oportunidade é inovadora consiste em um fator crítico de sucesso na sua exploração (Martin \& Wilson, 2016).

A criatividade pode ser definida como a demonstração de imaginação e originalidade, que leva além do modo cotidiano de pensar. Expande ou até mesmo quebra regras convencionais e fornece a base para a inovação e o crescimento do negócio. A capacidade criativa de associar domínios de conhecimento até então desconectados é uma tarefa na qual os empreendedores são particularmente eficientes. Essas associações geram inovações e, por conseguinte, novas oportunidades de negócio (Fillis \& Rentschler, 2010).

Diferentes atitudes em relação ao risco e às mudanças afetam o potencial criativo, mas as organizações de todos os portes estão percebendo os benefícios de desenvolver uma orientação criativa. Empreendedores mais criativos aceitam melhor o risco a fim de abrir novos caminhos e gerar inovação (Fillis \& Rentschler, 2010). Contudo, Martin e Wilson (2016) afirmam que os estudos sobre criatividade e empreendedorismo revelam que o caminho para novas ideias é complexo, interativo e pode passar por muitas falhas até que chegue ao sucesso final.

Ward (2004) aponta a existência de uma variedade de processos pelos quais empreendedores podem modificar, estender ou transformar seu conhecimento armazenado. Em especial, o autor destaca a combinação conceitual, definida como um processo pelo qual ideias ou conceitos previamente separados são mentalmente fundidos. Na visão do autor, essa é uma característica relevante para empreendedores em busca de novas ideias a serem exploradas comercialmente. Outro processo criativo, 
destacado por Ward (2004), é o raciocínio analógico que tem como objetivo aplicar conhecimentos de um domínio para auxiliar a compreensão ou o desenvolvimento de ideias em outro.

Baron (2006) destaca que a criatividade elevada ajuda empreendedores a identificarem novas soluções às necessidades do mercado e dos clientes, com base em informações existentes, e a imaginarem novos produtos e serviços que não existem no momento. Segundo o autor, empreendedores tendem a obter desempenho mais alto em testes de criatividade do que indivíduos não empreendedores.

As manifestações primárias da criatividade despontam na inovação em tarefas cotidianas por meio de novos arranjos que melhoram a utilização dos recursos à disposição do empreendedor e, consequentemente, geram maior valor econômico. Ser um empreendedor criativo é, portanto, ter capacidade de integrar, combinar e selecionar os recursos, organizando-os e empregando-os na resolução de problemas (Milan et al., 2011).

Em empresas menores, a criatividade é potencialmente mais útil como alternativa para superar barreiras em termos de aquisição de recursos e redução de custos. Muitas destas organizações têm conhecimentos especializados relacionados ao seu domínio de atuação, mas não possuem experiência ou tempo necessários para desenvolver maneiras formais de geração de estratégias criativas futuras, como ocorre na organização maior (Fillis \& Rentschler, 2010).

Apesar da sua relevância para a atividade empreendedora, Martin e Wilson (2016) afirmam que falta um exame científico detalhado do papel da criatividade no processo de reconhecimento de oportunidades. Fillis e Rentschler (2010) sugerem pesquisas que aprofundem o conhecimento sobre como a criatividade pode ser usada para lidar com a ambiguidade na tomada de decisões. A ambiguidade, segundo os autores, refere-se à existência de interpretações múltiplas e conflitantes em relação a uma situação organizacional. Para os autores, a criatividade deve ser estudada por meio de abordagens qualitativas capazes de capturar a natureza e o significado da experiência criativa na perspectiva dos próprios participantes da pesquisa, ao invés do emprego de medidas de frequência ou respostas a eventos.

\section{Capital Social}

Um conjunto de artigos revisados enfatiza a importância das redes e do capital social inerente a elas na criação de novos empreendimentos (Baron, 2006; De Carolis \& Saparito, 2006; Marvel et al., 2016; Yang \& Zhang, 2015).

O capital social se manifesta através das conexões externas do indivíduo e seus efeitos positivos fluem do acesso à informação, da influência e da solidariedade à disposição do empreendedor; elas podem contribuir para o sucesso do empreendedor na medida em que estes utilizam seus contatos em prol de seu empreendimento (De Carolis \& Saparito, 2006).

De Carolis e Saparito (2006) veem o capital social como um construto multidimensional, formado pelas dimensões estrutural, relacional e cognitiva. A dimensão estrutural refere-se à estrutura da rede e 
à existência ou não de conexões entre os atores, incluindo as conexões diretas e laços indiretos. $\mathrm{O}$ posicionamento dentro de uma rede é importante na medida em que garante acesso diferencial à informação. Já a dimensão relacional trata da natureza da relação pessoal entre membros específicos da rede, manifestada através de laços fortes ou laços fracos. A força das conexões, segundo os autores, é reflexo da quantidade de tempo, intensidade emocional, intimidade, confiança e serviços recíprocos que caracterizam o vínculo. Laços fortes, por exemplo, são tipicamente associados à confiança e facilitam o fluxo de informações relevantes. Por fim, a dimensão cognitiva diz respeito às representações compartilhadas ou maneiras comuns de olhar o mundo, que permitem aos indivíduos da rede dar sentido à informação e classifica-la em categorias perceptivas. Esses sistemas compartilhados facilitam a troca de informações, o aprendizado e a criação de conhecimento.

A amplitude das redes sociais dos empreendedores desempenha um papel relevante no reconhecimento de oportunidades, pois elas são uma importante fonte de informação que enriquece a base de conhecimentos do empreendedor e promove o desenvolvimento de estruturas cognitivas mais consistentes. Ao discutir oportunidades com outras pessoas, os empreendedores formam imagens mais precisas e úteis na avaliação do potencial destas (Baron, 2006).

Vínculos e alianças entre empresas geram uma série de vantagens associadas principalmente ao acesso direto ou indireto a recursos complementares, conhecimento compartilhado e colaboração entre integrantes da rede. Como produto final, têm-se o aprendizado aprimorado e o capital humano adquirido a partir dos laços da rede que pode gerar mais benefícios do que o conhecimento desenvolvido individualmente (Marvel et al., 2016).

Yang e Zhang (2015) defendem que uma grande rede social, dotada de laços fortes, traz informações confiáveis e oportunas que ajudam os empresários a reconhecer melhor os riscos envolvidos no negócio. Os autores apontam duas características das redes sociais que são importantes ao empreendedorismo: o tamanho e a diversidade da rede. Empreendedores ligados a uma grande rede podem reunir uma quantidade significativa e rica de informações. Além disso, o crescimento de uma rede tende a torná-la mais diversificada, pois os novos laços podem vir de diferentes indústrias, trazendo diferentes experiências educacionais e de vida. Essa diversificação proporciona aos membros da rede a verificação de informações coletadas de outros laços. Além disso, quanto mais diversificada a rede, mais novos conhecimentos e pontos de vista emergirão, auxiliando os empreendedores a triangular as informações que recebem.

Todavia, os autores reforçam que o seu estudo, assim como a maioria dos demais que buscaram associar a influência das redes sociais na avaliação do risco de exploração de oportunidades, utiliza como amostra um recorte transversal. Perde-se, desta forma, a capacidade de realizar inferências sobre um processo que é dinâmico - a exploração de oportunidades - e o quanto de erros no julgamento de riscos levam os empreendedores a alterar as suas redes nas próximas fases. Assim, Yang e Zhang (2015) sugerem a realização de pesquisas longitudinais para explicar de forma mais abrangente a dinâmica do processo. 
Embora os estudos demonstrem, de forma geral, a influência positiva das redes sobre a exploração de oportunidades, De Carolis e Saparito (2006) destacam que o seu impacto sobre a cognição pode também agir de modo negativo, impedindo a busca de oportunidades e citam a necessidade de estudos com esse objetivo.

\section{Reflexão Moral}

A reflexão moral é uma característica cognitiva apontada como capaz de influenciar a exploração de oportunidades empreendedoras (Bryant, 2009; Milan et al., 2011; Shepherd et al., 2015), visto que em situações de tomada de decisão sobre a exploração de oportunidades, alguns empreendedores são capazes de empregar a reflexão moral e autorregulação para orientar suas decisões, considerando os problemas do ponto de vista ético. Desta forma, as decisões empresariais, baseadas em percepções do comportamento moral, podem ter consequências substanciais na aquisição de recursos, no desenvolvimento de novos produtos e na exploração de oportunidades no mercado (Shepherd et al., 2015).

O sentimento de ser uma pessoa de bem (ou seja, ter uma identidade moral) e de fazer o bem (agir moralmente) emergem conjuntamente por meio de processos cognitivos sociais e em resposta a contextos situacionais. Comumente, empreendedores se deparam com circunstâncias nas quais devem optar por perseguir objetivos e interesses individuais ou manter a ética empresarial. Alguns empreendedores respondem muito mal a esse dilema, pois são moralmente inconscientes. A ausência de consciência moral eleva o risco do comportamento antiético na tomada de decisões e é, portanto, uma característica cognitiva fundamental para o exercício da atividade empresarial de maneira ética (Bryant, 2009). Além disso, Bryant (2009) e Shepherd et al. (2015) destacam uma relação positiva entre a reflexão moral e a confiança interpessoal, tornando as redes do empreendedor mais confiáveis.

Para Milan et al. (2011), os empreendedores devem orientar suas ações por valores pessoais, portando e exercendo altos padrões éticos de comportamento, o que garante a confiabilidade da organização e a sustentabilidade do negócio mesmo em momentos adversos.

Shepherd et al. (2015) apontam a necessidade de um melhor entendimento de como se dá a interação entre cognição e emoção. O estudo da reflexão moral e autorregulação pode fornecer subsídios interessantes para elucidar essa relação. Contudo, os autores reforçam que, para explorar esse campo, pesquisadores precisarão ser também empreendedores, inovando nos métodos para tatear um terreno ainda pouco explorado. Os autores sugerem a combinação de métodos, a utilização de experimentos, a utilização de dados secundários e dados em painel como alguns caminhos a serem seguidos. 


\section{Pensamento metacognitivo}

Outra característica capaz de moldar os modelos mentais de empreendedores é o pensamento metacognitivo (Krueger, 2007; Haynie \& Shepherd, 2009; Shepherd et al., 2015). A metacognição é um mecanismo psicológico responsável pela ligação entre os preconceitos cognitivos dos indivíduos (ou as heurísticas empregadas) e o estado de adaptação cognitiva que permite revisar suas estruturas cognitivas para a tomada de decisões. É o processo pelo qual indivíduos refletem e se conscientizam sobre o leque de estratégias disponíveis e apropriadas para aplicar em determinada circunstância. Indivíduos com habilidades metacognitivas reduzidas são menos propensos a adotar estratégias alternativas e, como resultado, são menos adaptáveis ao meio (Haynie \& Shepherd, 2009).

Como produto da metacognição tem-se a adaptabilidade cognitiva, definida por Haynie e Shepherd (2009) como a capacidade de alterar as políticas de decisão (em outras palavras, aprender) dado um feedback (input) do contexto ambiental no qual o processamento cognitivo está incorporado. Embora essa seja uma característica difícil de conquistar, está positivamente relacionada ao desempenho da tomada de decisão em ambientes complexos, dinâmicos e inerentemente incertos. Pensar de forma metacognitiva envolve, entre outras características, ser autoconsciente, pensar em voz alta, refletir, ser estratégico, planejar e se automonitorar. Para Mitchell et al. (2007), a metacognição envolve tanto a consciência da cognição quanto uma compreensão das estratégias para mudá-las.

Estar plenamente consciente das crenças profundas que moldam a ação torna muito mais fácil questioná-las e modificá-las (Krueger, 2007). Assim, em ambientes dinâmicos e desafiadores, a capacidade metacognitiva permite adaptar-se à incerteza, o que consiste em um recurso empresarial crítico e que permite o vislumbre de oportunidades. Empreendedores que utilizam mais o pensamento metacognitivo têm decisões menos incongruentes e confiam mais na intuição (Haynie \& Shepherd, 2009).

Mitchell et al. (2007) entendem que uma área de pesquisa potencialmente frutífera deve explorar como o pensamento metacognitivo pode ser posto em prática de forma deliberada por indivíduos empreendedores. Algumas reflexões apontadas pelos autores e que podem guiar futuros estudos são: indivíduos com maior e menor habilidade metacognitiva diferem em termos das estratégias utilizadas para avaliar uma oportunidade? Como a situação da empresa afeta a capacidade metacognitiva dos empreendedores? E, por fim, qual a relação existente entre a experiência acumulada e a capacidade metacognitiva?

Shepherd et al. (2015) advertem que, embora o pensamento metacognitivo possa retardar o processo de tomada de decisão, ao longo do tempo e do seu emprego repetitivo, o efeito de desaceleração tende a ser reduzido. Porém, estudos empíricos ainda são necessários sobre os aspectos temporais do pensamento metacognitivo para melhor embasar essas suposições. Outra lacuna de pesquisa apontada pelos autores é a possibilidade de explorar a relação entre a experiência, a tomada de decisão 
empreendedora e o pensamento metacognitivo, buscando responder se o acúmulo de experiência aumenta a capacidade de metacognição.

\section{Discussão}

Após a revisão de literatura realizada, que resultou nos dez aspectos cognitivos dos modelos mentais de empreendedores que influenciam a identificação e exploração de oportunidades e nas relações entre estes, propostas pelos autores supracitados, buscou-se sintetizar o conteúdo do capítulo anterior, analisando as contribuições apresentadas e estabelecendo um conjunto de proposições teóricas que possam ser averiguadas empiricamente em futuros estudos. As proposições são apresentadas e explanadas a seguir:

Proposição 1: A experiência prévia contribui para a geração de um capital social que pode ser aproveitado em favor da exploração de oportunidades.

Empreendedores seriais ou de portfólio, portanto experientes, possuem uma rede de contatos, estabelecida ao longo do tempo, que pode ser utilizada como base de informação para identificar e explorar oportunidades de negócios subsequentes e tirar proveito da rede em favor do novo negócio, diferentemente dos empreendedores iniciais (Westhead et al., 2005).

Proposição 2: A experiência prévia torna os empreendedores mais preparados para reconhecer oportunidades, avaliar o ambiente e torná-los mais propensos ao risco destas oportunidades.

As experiências empreendedoras anteriores geram um corpo de habilidades específicas que permitem que os indivíduos lidem melhor com a quantidade de informações que enfrentam ao avaliar os riscos de um negócio e decidir por explorar ou refutar oportunidades (Shane, 2000; Ward, 2004; Baron, 2006; Alvarez \& Barney, 2010; Milan et al., 2011; Marvel et al., 2016; Wood et al., 2014).

Proposição 3: Episódios de fracasso anterior influenciam negativamente o otimismo, o excesso de confiança e a propensão ao risco, influenciando negativamente a exploração de oportunidades.

Empreendedores que vivenciaram experiências fracassadas na condução de seus negócios tendem a avaliar futuras oportunidades de modo menos otimista (Mitchell et al., 2008). Além disso, o fracasso anterior reduz o excesso de confiança. Os erros cometidos anteriormente tornam os indivíduos mais conscientes de suas limitações e podem reduzir neles o ímpeto de envolver-se em novas oportunidades empreendedoras (Wood et al., 2014).

Proposição 4: Há uma relação entre otimismo e excesso de confiança e o aumento de ambos torna os empreendedores mais propensos ao risco e à exploração de oportunidades.

Empreendedores mais otimistas apresentam maior excesso de confiança e o viés de confirmação, não percebendo as limitações e imprecisões de suas projeções e buscando coletar informações e evidências que confirmem as suas crenças (Sánchez et al., 2011). Embora contribua positivamente em diversas situações do mundo dos negócios, o otimismo tem efeitos negativos quando indivíduos com esta característica comportamental esperam resultados positivos mesmo quando tal expectativa não é 
racionalmente justificada. Tanto o otimismo quanto o excesso de confiança aumentam a propensão ao risco, mesmo que sem uma avaliação consistente do mesmo (Shepherd et al., 2015) e tornam empreendedores mais receptivos às oportunidades.

Proposição 5: A criatividade é embasada pelo domínio do conhecimento e gera uma maior possibilidade de explorar oportunidades.

Empreendedores com maior conhecimento específico de características técnicas dos produtos, de seus processos fabris e operações, além de conhecimentos específicos do ambiente setorial, apresentam maior capacidade de desenvolver soluções criativas para os problemas e para o melhor aproveitamento dos recursos (Fillis \& Rentschler, 2010). Empreendedores mais criativos também são mais propensos ao risco na medida em que implantar ideias inovadoras é um processo complexo, interativo e no qual podem ocorrer diversas falhas até que se chegue ao resultado esperado (Martin \& Wilson, 2016). Essa característica torna, portanto, empreendedores mais propensos à exploração de oportunidades inovadoras.

Proposição 6: O pensamento metacognitivo reduz o excesso de confiança e torna as decisões de exploração de oportunidade mais consistentes.

O emprego da metacognição leva os indivíduos a um estado constante de reflexão sobre suas crenças e estruturas cognitivas empregadas na tomada de decisão e de adaptação para adotar estratégias mais consistentes ao ambiente (Haynie \& Shepherd, 2009). Refletir sobre suas crenças, ou seja, ser autoconsciente, reduz o excesso de confiança e consequentemente torna o empreendedor mais crítico para lidar com a avaliação de risco e aceitá-lo de forma consciente (De Carolis \& Saparito, 2006). Essa relação pode, portanto, influenciar a exploração de oportunidades de maneira que os empreendedores tomarão decisões mais conscientes e embasadas.

Proposição 7: A experiência prévia aumenta a capacidade de pensamento metacognitivo e torna as decisões de exploração de oportunidade mais consistentes..

A vivência de situações, contextos e decisões diversas torna os empreendedores mais conscientes de seus pontos fortes e de suas limitações, potencializando o pensamento metacognitivo (Krueger, 2007). Neste sentido, o acúmulo de experiência viria acompanhado de uma maior capacidade metacognitiva dos empreendedores (Shepherd et al., 2015).

Proposição 8: O capital social potencializa a reflexão moral, influenciando a exploração de oportunidades.

Indivíduos com um maior capital social, dotado de laços fortes, tendem a empregar a reflexão moral na avaliação de suas decisões (Bryant, 2009), analisando-as do ponto de vista moral e ético e levando em consideração seus impactos sobre o bem-estar comum (Shepherd et al., 2015), o que influencia as suas decisões de exploração de oportunidades sob essa ótica. 


\section{Considerações finais}

O campo de estudos do empreendedorismo está à beira de um avanço significativo na medida em que mais pesquisadores empreguem ferramentas da ciência cognitiva para responder a questões importantes sobre os empreendedores (Krueger, 2007). Como apontado por Mitchell et al. (2007), há pouco conhecimento sobre o efeito de diferentes modelos mentais nas escolhas e decisões tomadas por empreendedores frente a uma oportunidade de negócio.

A revisão de literatura aqui apresentada, e em maior grau as proposições levantadas a partir desta, revela uma série de lacunas de pesquisa e pontos que carecem de aprofundamento em estudos empíricos de forma a desenvolver um melhor entendimento sobre como características cognitivas interferem na identificação e exploração de novos de negócios. Essas proposições podem ser entendidas como estradas capazes de levar a uma melhor compreensão do fenômeno, seja estudando-as de forma isolada ou conjunta, para entender as relações existentes entre os aspectos cognitivos e como estes, em conjunto, moldam a avaliação de um empreendedor frente a uma oportunidade.

Os modelos mentais são representações de mundo, construídos de forma complexa e ao longo da vida. Optou-se neste estudo, por focar nos aspectos cognitivos que influenciam os modelos mentais. Há, porém, outras características que moldam as decisões empreendedoras de forma tão intensa quanto a cognição. Os aspectos afetivos, por exemplo, representam outra via de pesquisa relevante e promissora para interessados em compreender como empreendedores tomam suas decisões sobre a exploração de oportunidades e que não foram abordados nesse estudo. Fatores como intuição (Baldacchino et al., 2015; Grégoire et al., 2015), medo (Cacciotti \& Hayton, 2015; Grégoire et al., 2015), influências familiares (Teixeira, Ducci, Sarrassini, Munhê \& Ducci et al., 2011), dentre outros, também podem fornecer subsídios importantes para melhor compreensão do processo empreendedor.

Na construção deste artigo, empenhou-se mais em gerar perguntas do que respostas. Propôs-se aqui uma ampla revisão de literatura, com o intuito de reunir subsídios teóricos que embasem futuros estudos empíricos, para averiguar o papel de modelos mentais sobre o processo de identificação e exploração de oportunidades empreendedoras. Procurou-se evidenciar a diversidade de oportunidades de pesquisa no campo da cognição empreendedora e a necessidade do empenho de pesquisadores interessados no tema para melhor elucidação dos processos cognitivos envolvidos na exploração de oportunidades empreendedoras.

\section{Referências}

Aliaga-Isla, R. \& Rialp, A. (2012). How do information and experience play a role in the discovery of entrepreneurial opportunities? The case of Latin-American immigrants in Barcelona. Latin American Business Review, 13(1), 59-80.

Alvarez, S. A. \& Barney, J. B. (2010). Entrepreneurship and epistemology: The philosophical underpinnings of the study of entrepreneurial opportunities. Academy of Management annals, 4(1), 557-583. 
Ardichvili, A., Cardozo, R. \& Ray, S. (2003). A theory of entrepreneurial opportunity identification and development. Journal of Business venturing, 18(1), 105-123.

Armstrong, S. J., Cools, E. \& Sadler-Smith, E. (2012). Role of cognitive styles in business and management: Reviewing 40 years of research. International Journal of Management Reviews, 14(3), 238-262.

Badke-Schaub, P., Neumann, A., Lauche, K. \& Mohammed, S. (2007). Mental models in design teams: a valid approach to performance in design collaboration?. CoDesign, 3(1), 5-20.

Baldacchino, L., Ucbasaran, D., Cabantous, L. \& Lockett, A. (2015). Entrepreneurship research on intuition: A critical analysis and research agenda. International Journal of Management Reviews, 17(2), 212-231.

Baron, R. A. (2006). Opportunity recognition as pattern recognition: How entrepreneurs "connect the dots" to identify new business opportunities. Academy of management perspectives, 20(1), 104-119.

Baron, R. A. \& Ward, T. B. (2004). Expanding entrepreneurial cognition's toolbox: Potential contributions from the field of cognitive science. Entrepreneurship Theory and Practice, 28(6), 553-573.

Borges, A. T. (1997). Um estudo de modelos mentais. Investigações em ensino de ciências, 2(3), 207266.

Boszczowski, A. K. \& Teixeira, R. M. (2012). O empreendedorismo sustentável e o processo empreendedor: em busca de oportunidades de novos negócios como solução para problemas sociais e ambientais. Revista Economia \& Gestão, 12(29), 141-168.

Brønn, P. S. \& Brønn, C. (2003). A reflective stakeholder approach: Co-orientation as a basis for communication and learning. Journal of Communication Management, 7(4), 291-303.

Bryant, P. (2009). Self-regulation and moral awareness among entrepreneurs. Journal of Business Venturing, 24(5), 505-518.

Cacciotti, G. \& Hayton, J. C. (2015). Fear and entrepreneurship: A review and research agenda. International Journal of Management Reviews, 17(2), 165-190.

Campos, H. M. \& Muñoz, A. M. S. (2009). Ideias de Negócios e Modelos Mentais: um estudo exploratório quantitativo. RBGN: Revista Brasileira de Gestão de Negócios, 11(32), 276-288.

Cassar, G. (2010). Are individuals entering self-employment overly optimistic? An empirical test of plans and projections on nascent entrepreneur expectations. Strategic Management Journal, 31(8), 822-840.

Chapman, J. A. \& Ferfolja, T. (2001). Fatal flaws: the acquisition of imperfect mental models and their use in hazardous situations. Journal of Intellectual Capital, 2(4), 398-409.

Chermack, T. J. (2003). Mental models in decision making and implications for human resource development. Advances in developing human resources, 5(4), 408-422.

Cortez, A. E. G., Ferreira, T. B., Ferreira, C. D. M. \& Araújo, A. G. (2016). Cognição e afetividade nas trajetórias empreendedoras das mulheres da cidade do Natal-RN. Revista de Empreendedorismo e Gestão de Pequenas Empresas, 5(2), 24-50. 
Costa, C. R. F., Machado, H. V. \& Vieira, F. G. D. (2007). Comportamento Empreendedor na Exploração de Oportunidades: história oral sobre o caso de uma indústria do setor alimentício. Desenvolvimento em questão, 5(10), 75-95.

De Carolis, D. M. \& Saparito, P. (2006). Social capital, cognition, and entrepreneurial opportunities: A theoretical framework. Entrepreneurship theory and practice, 30(1), 41-56.

De Toni, D. \& Milan, G. S. (2008). A relação entre os modelos mentais dos empreendedores e o desempenho organizacional: Um estudo exploratório em duas empresas do setor metalmecânico. READ-Revista Eletrônica de Administração, 14(3), 623-649.

Denyer, D. \& Tranfield, D. (2009). Producing a systematic review. The Sage Handbook Of Organizational Research Methods, 671-689.

Dew, N., Grichnik, D., Mayer-Haug, K., Read, S. \& Brinckmann, J. (2015). Situated entrepreneurial cognition. International Journal of Management Reviews, 17(2), 143-164.

Dhanaraj, C. \& Khanna, T. (2011). Transforming mental models on emerging markets. Academy of Management Learning \& Education, 10(4), 684-701.

Dimov, D. (2011). Grappling with the unbearable elusiveness of entrepreneurial opportunities. Entrepreneurship Theory and Practice, 35(1), 57-81.

Dutta, D. K. \& Crossan, M. M. (2005). The nature of entrepreneurial opportunities: Understanding the process using the 4I organizational learning framework. Entrepreneurship Theory and Practice, 29(4), 425-449.

Fillis, I. \& Rentschler, R. (2010). The role of creativity in entrepreneurship. Journal of Enterprising Culture, 18(01), 49-81.

Fiorin, M. M. B., de Mello, C. M. \& Machado, H. V. (2010). Empreendedorismo e Inovação: Análise dos índices de inovação dos empreendimentos brasileiros com base nos relatórios do GEM de 2006, 2007 e 2008. Revista de Administração da UFSM, 3(3), 411-423.

Grégoire, D. A., Cornelissen, J., Dimov, D. \& Van Burg, E. (2015). The mind in the middle: Taking stock of affect and cognition research in entrepreneurship. International Journal of Management Reviews, 17(2), 125-142.

Haynie, M. \& Shepherd, D. A. (2009). A measure of adaptive cognition for entrepreneurship research. Entrepreneurship Theory and Practice, 33(3), 695-714.

Hisrich, R. D., Peters, M. P. \& Shepherd, D. A. (2014). Empreendedorismo-9. AMGH Editora.

Hmieleski, K. M. \& Baron, R. A. (2009). Entrepreneurs' optimism and new venture performance: A social cognitive perspective. Academy of management Journal, 52(3), 473-488.

Hogarth, R. M. \& Karelaia, N. (2012). Entrepreneurial success and failure: Confidence and fallible judgment. Organization Science, 23(6), 1733-1747.

Hsieh, R. M. \& Kelley, D. J. (2016). The Role of Cognition and Information Access in the Recognition of Innovative Opportunities. Journal of Small Business Management, 54, 297-311.

Krueger, N. F. (2007). What lies beneath? The experiential essence of entrepreneurial thinking. Entrepreneurship theory and practice, 31(1), 123-138. 
Martin, L. \& Wilson, N. (2016). Opportunity, discovery and creativity: A critical realist perspective. International Small Business Journal, 34(3), 261-275.

Marvel, M. R., Davis, J. L. \& Sproul, C. R. (2016). Human capital and entrepreneurship research: A critical review and future directions. Entrepreneurship Theory and Practice, 40(3), 599-626.

Milan, G. S., De Toni, D., Dorion, E. \& Schuler, M. (2011). A influência dos modelos mentais dos empreendedores no desempenho de suas organizações. GESTÃO. Org-Revista Eletrônica de Gestão Organizacional, 8(3), 355-381.

Mitchell, R. K., Busenitz, L. W., Bird, B., Marie Gaglio, C., McMullen, J. S., Morse, E. A. \& Smith, J. B. (2007). The central question in entrepreneurial cognition research 2007. Entrepreneurship theory and practice, 31(1), 1-27.

Mitchell, R. K., Busenitz, L., Lant, T., McDougall, P. P., Morse, E. A. \& Smith, J. B. (2002). Toward a theory of entrepreneurial cognition: Rethinking the people side of entrepreneurship research. Entrepreneurship theory and practice, 27(2), 93-104.

Mitchell, R. K., Mitchell, J. R. \& Smith, J. B. (2008). Inside opportunity formation: Enterprise failure, cognition, and the creation of opportunities. Strategic Entrepreneurship Journal, 2(3), 225-242.

Park, O. C. \& Gittelman, S. S. (1995). Dynamic characteristics of mental models and dynamic visual displays. Instructional Science, 23(5-6), 303-320.

Pryor, C., Webb, J. W., Ireland, R. D. \& Ketchen Jr., D. J. (2016). Toward an integration of the behavioral and cognitive influences on the entrepreneurship process. Strategic Entrepreneurship Journal, 10(1), 21-42.

Sánchez, J. C., Carballo, T. \& Gutiérrez, A. (2011). The entrepreneur from a cognitive approach. Psicothema, 23(3), 433-438.

Senge, P. M. (2013). A quinta disciplina: arte e prática da organização que aprende. 29.ed. Rio de Janeiro: Best Seller.

Senge, P. M. (1992). Mental models. Planning review, 20(2), 4-44.

Shane, S. (2000). Prior knowledge and the discovery of entrepreneurial opportunities. Organization science, 11(4), 448-469.

Shepherd, D. A., Williams, T. A. \& Patzelt, H. (2015). Thinking about entrepreneurial decision making: Review and research agenda. Journal of management, 41(1), 11-46.

Teece, D. J. (2007). Explicating dynamic capabilities: the nature and microfoundations of (sustainable) enterprise performance. Strategic management journal, 28(13), 1319-1350.

Teixeira, R. M., Ducci, N. P. C., Sarrassini, N. S., Munhê, V. P. C. \& Ducci, L. Z. (2011). Empreendedorismo jovem e a influência da família: a história de vida de uma empreendedora de sucesso. REGE Revista de Gestão, 18(1), 3-18.

Ucbasaran, D., Westhead, P., Wright, M. \& Flores, M. (2010). The nature of entrepreneurial experience, business failure and comparative optimism. Journal of Business Venturing, 25(6), 541555.

Ward, T. B. (2004). Cognition, creativity, and entrepreneurship. Journal of business venturing, 19(2), 173-188. 
Westbrook, L. (2006). Mental models: a theoretical overview and preliminary study. Journal of Information Science, 32(6), 563-579.

Westhead, P., Ucbasaran, D. \& Wright, M. (2005). Experience and cognition: do novice, serial and portfolio entrepreneurs differ?. International Small Business Journal, 23(1), 72-98.

Wood, M. S. \& McKelvie, A. (2015). Opportunity evaluation as future focused cognition: Identifying conceptual themes and empirical trends. International Journal of Management Reviews, 17(2), 256277.

Wood, M. S., McKelvie, A. \& Haynie, J. M. (2014). Making it personal: Opportunity individuation and the shaping of opportunity beliefs. Journal of Business Venturing, 29(2), 252-272.

Yang, J. \& Zhang, J. (2015). Social networks, cognition and risk recognition in new ventures: Evidence from China. Journal of Developmental Entrepreneurship, 20(02), 1550012. 